\title{
Public knowledge, perception, and experience with generic medications in Saudi Arabia
}

Omar A. Almohammed, PharmD, PhD, Leen A. Aldwihi, PharmD candidate, Abdullah A. Alhifany, PharmD.

\begin{abstract}

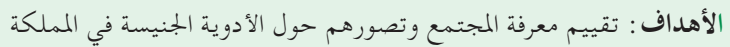

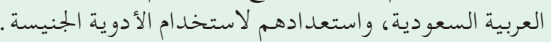

المنهجية: دراسة مقطعية قائمة على استبيان الكتروني، تم جمع البيانات

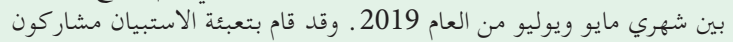

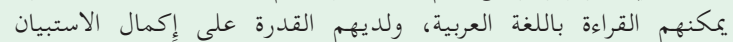

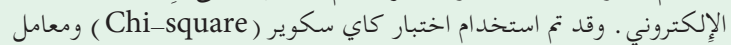

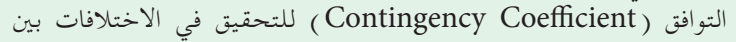

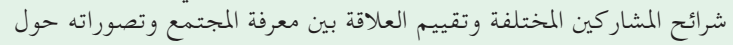

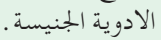

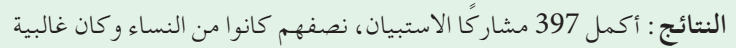

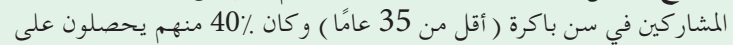

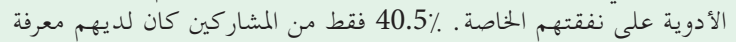

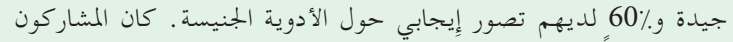

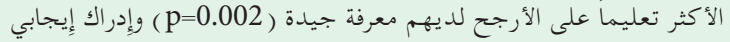

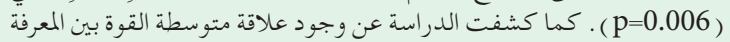

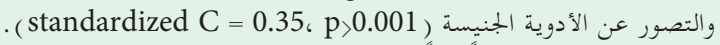

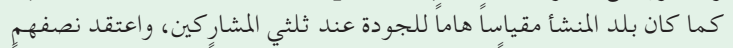

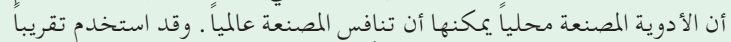
نصف المشار كين الأدوية الجنيسة سابقاً وكان معظمهـم راضين عن تجربتهـم .

الخلاصة : كشفت الدراسة عن مستوى معرفي متدني حول الأدوية الجنيسة

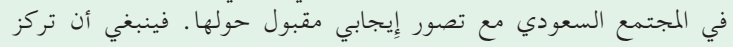

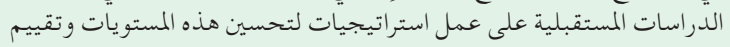

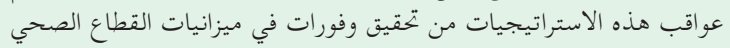
مع الحفاظ على جودة الرعاية الصحية.
\end{abstract}

Objectives: To assess the public knowledge and perception about generic medications in Saudi Arabia, and their willingness to use generic medications.

Methods: This cross-sectional, online-questionnairebased study was conducted between May and July 2019, including participants who can read and complete an Arabic online survey. Chi-square test and contingency coefficient were used to investigate differences in different segments of participants and assess the association between knowledge and perception.
Results: A total of 397 participants have completed the survey. One-half of them were female, the majority were of young age ( $<35$ years), and $40 \%$ of them were buying their medications independently. Only $40.5 \%$ of participants had adequate knowledge and $60 \%$ of them had positive perception on generics. Participants with higher level of education were more likely to have adequate knowledge $(p=0.002)$ and positive perception $(p=0.006)$. The study found a moderate relationship between knowledge and perception about generics (standardized $\mathrm{C}=0.35$, $p<0.001)$. The country of origin for medications was a significant indicator of quality for two-thirds of participants, and one-half of them believed that local generics can compete with imported ones. About onehalf of participants used generics and the majority of them were satisfied with their experience.

Conclusion: There is a general lack of knowledge, while having a positive perception on generic medications among the general public in Saudi Arabia. Future studies should focus on strategies to improve it and assess its cost-savings consequences while maintaining quality of care.

Keywords: generic, Saudi Arabia, knowledge, perception, experience

Saudi Med J 2020; Vol. 41 (4): 413-420 doi: 10.15537/smj.2020.4.24992

From the Department of Clinical Pharmacy (Almohammed, Aldwibi), College of Pharmacy, King Saud University, Riyadh, and from the Department of Clinical Pharmacy (Alhifany), College of Pharmacy, Umm Al-Qura University Makkah, Makkah, Kingdom of Saudi Arabia.

Received 14th October 2019. Accepted 4th February 2020.

Address correspondence and reprint request to: Dr. Omar A. Almohammed, Department of Clinical Pharmacy, College of Pharmacy, King Saud University, Riyadh, Kingdom of Saudi Arabia. E-mail: oalmohammed@ksu.edu.sa

ORCID ID: http://www.orchid.org/0000-0002-3792-4106 
$\mathrm{H}$ ealthcare costs continues to rise over the years, which urge for cost containment strategies to be implemented. Cost sharing, managed care competition, reference pricing, and generic substitution are the main proven cost-saving strategies proposed in the literature. ${ }^{1}$ Generic drugs are supposed to be inexpensive and equally effective to their brand counterparts. ${ }^{2}$ Warraich et $\mathrm{al}^{3}$ analyzed trends in use and healthcare expenditure of the brand atorvastatin (Lipitor ${ }^{\odot}$ ) and found that the introduction of generic atorvastatin in the United States (US) market at the end of 2011 led to a $28 \%$ reduction; yet, the persistent prescribing of Lipitor ${ }^{\circledR}$ resulted in US $\$ 2.1$ billion in excess expenditure from 2012 to $2014 .^{3}$ Multiple challenges hinder the broad use of generic medications worldwide, such as inadequate knowledge and negative perceptions as well as the lack of polices that enforce generic medications substitution such as the ones implemented in many developed countries. ${ }^{4}$

In 2017, Saudi Arabia has allocated 32 billion US dollar for healthcare and social spending with a $20 \%$ increase over 2016 and the spending on pharmaceutical products is considered one of the driving factors for the rising healthcare costs in Saudi Arabia. ${ }^{5}$ In light of the current economical vision 2030 for the kingdom, there is an urgent need to bring the cost of the Saudi healthcare system to a sustainable level. Thus, the Saudi government is aiming to reduce the spending on the healthcare system, while improving the quality of care provided to its citizens and residents. Hence, the substitution of brand medications with their therapeutically equivalent generics should offer a significant opportunity for cost saving without jeopardizing the quality of care. ${ }^{1,3} \mathrm{~A}$ study was conducted in the Eastern region of Saudi Arabia to investigate the prescribing pattern of generic medications compared to their branded counterparts for type 2 diabetes and hypertension medications. The study found that among all prescribed medications only $26.9 \%$ were generics and the rate was higher in the governmental compared to the private hospitals. ${ }^{6}$ The study concluded that there was an underutilization of generic medications in these 2 major health conditions in Saudi Arabia, which represent an oportunity for a cost-saving initiative. ${ }^{6}$

Disclosure. Authors have no conflict of interests, and the work was not supported or funded by any drug company. This study was funded by the Researcher Supporting Project (no. RSP-2019/77), King Saud University, Riyadh, Kingdom of Saudi Arabia.
The quality of medications, generics in particular, is an important constraint that has to be guaranteed before encouraging the public to use generic medications more often. The Saudi Food and Drug Authority (SFDA) is working to ensure the safety and efficacy of all medications in the country. However, the quality of medications was recognized as a major issue by a panel of experts in Saudi Arabia. Based on the gaps that were identified by the experts, the panel discussion was concluded with approximately 10 recommendations that can be adopted by the authority to address the issue of generic medications' quality in the country. ${ }^{7}$ Among these recommendations are the need for the SFDA to conduct its own bioequivalence studies; to ensure the quality of these products, to establish a national regulations and standards, to direct the switching from brands to generics and among different generics of the same medication, and conduct a national outcomes' studies to assess the quality of medications in general, and generics or biosimilars medications in particular. ${ }^{7}$ If these recommendations where to be adopted, the quality of medications will improve, which will have a significant impact on providing high quality of care without affecting the national budget for healthcare services.

There is a paucity of research regarding public knowledge and perception on generic medications in Saudi Arabia. Only one study was conducted to assess the public perception on generic mediations, but it did not assess their knowledge on it. $^{8}$ More than $60 \%$ of participants preferred the use of brand medications over generics, approximately $40 \%$ of participants believed that generics were less effective, and $25 \%$ had more adverse effects than their comparator brands. ${ }^{8}$ Therefore, the current study was conducted to assess the current public knowledge and perception on generic medications and their willingness to use them as an alternative to branded ones in Saudi Arabia. It also aimed to determine the public perception on locally manufactured medications when compared to the imported ones.

Methods. A cross-sectional, questionnaire-based study was conducted to assess the current public knowledge and perception on generic medications in Saudi Arabia, and their view of locally manufactured generics. Participants who can read Arabic and have the capability to complete an online survey were included in the study. An online questionnaire was developed and distributed to facilitate the data collection process.

A specific questionnaire was developed for this study, which composed of 4 sections. A demographic section (8 items), participants' knowledge on generic 
medications (5 items), participants perception on the use of generic medications in general, and the locally manufactured versus (vs.) the imported generic medications in particular (10 items), and participants' previous experience with generic medications (5 items). A copy of the Arabic and English versions of the questionnaire were provided in the supplementary material.

The first section consisted of 5 polar questions (yes/no) which intended to assess the current knowledge on generic medications among the general public and different segments of the population. Adequate level of knowledge was defined as answering correctly for 3 questions out of 5 . After responding to the items in the first section, a common definition for generic medications was presented with few examples to the participants to standardize the definition of generic medications among the participants. The definition that we used was published by the SFDA in Arabic and translated to English. Generic medications have the same mechanism of action, use, dosage, and effect as their reference original medication, and must have the same quality and safety standards of the original medication. ${ }^{\text {? }}$

The second section consisted of 10 statements, regarding the participants' opinion, thoughts, feelings, preferences, and motives toward the use of generic medications. The participants recorded their responses to these items on a 5-point Likert scale (from strongly agree to strongly disagree). The participants who responded positively to more than $50 \%$ of the items were considered to have a positive perception on generics in general, or the locally manufactured, in particular. The last 3 items in this section were then assessed individually, as they represented the participants' perception on generics manufactured locally, regionally, or internationally.

The third section consisted of 3 close-ended questions (yes/no), and 2 statements on the participants' experience with generic medications. They recorded their responses on a Likert scale for one item and selected from a list of choices for the other. This section was intended to investigate the relationship between the participants' knowledge and perception regarding generic medications and their use.

The items on the questionnaire were checked for clarity and validity by 3 independent researchers before the distribution of the questionnaire to the respondents. After sending the questionnaire to a small pilot group of participants, minor edits were made on the questionnaire based on comments from the pilot group, then it was distributed to a larger sample. The knowledge items in the questionnaire had an acceptable level of internal reliability with a Cronbach's $\alpha$ of 0.72 . Whereas for the perception items, one item was deleted to improve the internal reliability of the scale to reach to an acceptable reliability for the remaining items with a Cronbach's $\alpha$ of 0.87 .

Convenience sampling was used by inviting people through WhatsApp ${ }^{\oplus}$ to participate in the study by filling an online questionnaire, and invitation message was sent to them to inform them on the purpose of the study. The use of WhatsApp ${ }^{\varpi}$ among Saudis is very common, and presumed to be appropriate for the distribution of the survey in order to reach to a diverse sample from different regions in the country. ${ }^{10}$ The data were collected over 3 months from May 2019 to July 2019, using an online survey tool for data collection (Microsoft Forms ${ }^{\oplus}$ ), and the obtained data were secured within an encrypted database. The design of the study and questionnaire were approved by the Institutional Review Board (IRB) at King Saud University, Riyadh, Saudi Arabia.

Statistical anaalysis. Descriptive statistics were used to describe the participants' demographics and their knowledge and perception on generic medications. Whereas for inferential statistics, Chi-square test was used to investigate differences in knowledge and perception on generics in different segments of participants, and contingency coefficient (C) calculation was used to investigate the association between knowledge and perception. The $\alpha$ level of $<0.05$ were used for statistical significance. The study assumed that $50 \%$ of the population will have an adequate knowledge of generic medications; based on that, a 95\% confidence level and 5\% margin of error the calculated sample size was found to be 385 . Internal reliability of the knowledge and perception items were checked using Cronbach's $\alpha$ statistics. The data from responses to the Likert scale items were coded into numbers from 1 to 5 (totally disagree to totally agree), and transformed when necessary. The data were coded, checked for accuracy and analyzed using the IBM SPSS Statistics for Windows, version 25 (IBM Corp, Armonk, NY, USA).

Results. A total of 397 questionnaires were completed by participants. Most of the respondents were female $(53.6 \%)$, of young age $(<35$ years $-70 \%)$, holding a graduate or post-graduate degree $(74 \%)$, and $47.4 \%$ of the respondents were employed. Approximately $40 \%$ of the participants reported receiving their medications though governmental coverage and another $40 \%$ were acquiring it through out of pocket payment. The 
respondents' demographics were summarized in Table 1. Respondents' knowledge on generic medications. Only $40.5 \%$ of participants had an adequate knowledge of generic medications. However, that was significantly dependent on the highest level of educational achievement for the participant $(p=0.002)$; participants with a higher level of education were more likely to have an adequate knowledge of generics. Moreover, employed participants or those with higher income were more likely to have an adequate knowledge on generics. Otherwise, this finding was consistent among different age groups, males and females, and people paying out of pocket for their medications or acquiring them from governmental institutions or through insurance

Table 1 - Demographic characteristics for participants ( $N=397$ ).

\begin{tabular}{|c|c|}
\hline Demographic characteristics & n (\%) \\
\hline \multicolumn{2}{|l|}{ Age } \\
\hline$<18$ years & $21 \quad(5.3)$ \\
\hline $18-25$ years & $158(39.8)$ \\
\hline $26-35$ years & $101(25.4)$ \\
\hline $36-45$ years & $65(16.4)$ \\
\hline $46-60$ years & $49(12.3)$ \\
\hline Older than 60 & $3(0.8)$ \\
\hline \multicolumn{2}{|l|}{ Gender } \\
\hline Male & $184(46.4)$ \\
\hline Female & $213(53.6)$ \\
\hline \multicolumn{2}{|l|}{ Highest level of education } \\
\hline Less than high school & $13(3.3)$ \\
\hline High school & $81(20.4)$ \\
\hline Diploma & $8(2.0)$ \\
\hline Bachelor degree & $210(52.9)$ \\
\hline $\begin{array}{l}\text { Higher education (master degree or } \\
\text { more) }\end{array}$ & $85(21.4)$ \\
\hline \multicolumn{2}{|l|}{ Average monthly income } \\
\hline Less than 3000 Saudi Riyals (SR) & $111(28.7)$ \\
\hline 3000-7000 SR & $46(11.9)$ \\
\hline 7001-12000 SR & $77(19.9)$ \\
\hline $12001-18000 \mathrm{SR}$ & $78(20.2)$ \\
\hline $18001-25000 \mathrm{SR}$ & $27 \quad(7.0)$ \\
\hline More than 25000 SR & $48(12.4)$ \\
\hline \multicolumn{2}{|l|}{ Job status } \\
\hline Employed & $188(47.4)$ \\
\hline Unemployed & $193(48.6)$ \\
\hline Retired & $16(4.0)$ \\
\hline \multicolumn{2}{|l|}{ Health status } \\
\hline Healthy & $327(82.4)$ \\
\hline Have one chronic condition & $44(11.1)$ \\
\hline Have multiple chronic conditions & $14 \quad(3.5)$ \\
\hline Have a genetic condition & $12(3.0)$ \\
\hline \multicolumn{2}{|c|}{$\begin{array}{l}\text { Major source of payment to cover the cost of } \\
\text { medications }\end{array}$} \\
\hline Governmental coverage & $157(39.6)$ \\
\hline Insurance coverage & $81(20.4)$ \\
\hline Out of pocket & $159(40.0)$ \\
\hline
\end{tabular}

coverage. The participants' knowledge of generics based on their demographics were presented in Table 2.

Respondents' perception on generic medications. Approximately $60 \%$ of participants had an overall positive perception on generic medications. Similar to the knowledge variable, this was significantly dependent on the highest level of educational achievement for the participant $(p=0.006)$; participants with a higher level of education were more likely to have a positive perception on generics. Moreover, the overall positive perception was dependent on the participants' age $(p=0.008)$ and income levels $(p=0.030)$, without a consistent pattern for both variables. Otherwise, this finding was consistent among males and females, job and health status, and people paying out of pocket for their medications or acquiring them from governmental institutions or through insurance coverage. The participants' perception on generics based on their demographics were presented in Table 2 .

Participants' beliefs on and experiences with generics. Approximately two-thirds of participants believed that the country of origin for a medication is a significant predictor of quality and effectiveness, and that did not differ between the participants based on their knowledge nor perception on generics. However, participants with adequate knowledge were more likely to ask about the country of origin for medications compared to participants with inadequate knowledge $(71.4 \%$ vs. $34.7 \%, p<0.0001)$, and participants with positive perception about generics were more likely to ask about the country of origin for medications compared to participants with negative perception $(56.7 \%$ vs. $38.9 \%, p=0.0005)$. Although, one-half of participants believed that locally manufactured generics were of high quality and can compete with the imported ones, this was significantly dependent on the participants' knowledge and perception on generics (Table 3). About $60 \%$ of participants with adequate knowledge and $63 \%$ of participant with positive perception on generics, believed that locally manufactured generics were able to compete with their comparators imported from developed countries. In addition, this was proven true when compared locally manufactured generics to products of other regional countries (Table 3).

Approximately one-half of participants reported either using or having used generic medications in the past, more likely the ones with adequate knowledge and positive perception on generics than those with inadequate knowledge and negative perception (Table 4). Among the participants that used generics in the past, around two-thirds of them stated their willingness to re-use generic medications in the future, more likely the 
Knowledge and experience with generics ... Almohammed et al

Table 2 - Participants' knowledge and perception about generics.

\begin{tabular}{|c|c|c|c|c|c|c|}
\hline \multirow{2}{*}{ Demographics } & \multicolumn{3}{|c|}{ Knowledge (\%) } & \multicolumn{3}{|c|}{ Perception (\%) } \\
\hline & Adequate & Inadequate & $P$-value* & Positive & Negative & $P$-value \\
\hline Age (years) & & & 0.107 & & & $0.008^{\dagger}$ \\
\hline$<18$ & 14.3 & 85.7 & & 33.3 & 66.7 & \\
\hline $18-25$ & 38.6 & 61.4 & & 57.6 & 42.4 & \\
\hline $26-35$ & 42.6 & 57.4 & & 69.3 & 30.7 & \\
\hline $36-45$ & 46.2 & 53.8 & & 64.6 & 35.4 & \\
\hline $46-60$ & 46.9 & 53.1 & & 51.0 & 49.0 & \\
\hline$>60$ & 33.3 & 66.7 & & 100 & 00.0 & \\
\hline Gender & & & 0.085 & & & 0.334 \\
\hline Male & 45.1 & 54.9 & & 62.5 & 37.5 & \\
\hline Female & 36.6 & 63.4 & & 57.7 & 42.3 & \\
\hline Highest level of education & & & 0.002 & & & 0.006 \\
\hline Less than high school & 15.4 & 84.6 & & 38.5 & 61.5 & \\
\hline High school & 28.4 & 71.6 & & 49.4 & 50.6 & \\
\hline Diploma & 37.5 & 62.5 & & 37.5 & 62.5 & \\
\hline Bachelor degree & 40.9 & 59.1 & & 60.9 & 39.1 & \\
\hline Higher education & 55.3 & 44.7 & & 72.9 & 27.0 & \\
\hline Average monthly income (SR) & & & 0.001 & & & 0.030 \\
\hline$<3000$ & 37.9 & 62.1 & & 60.8 & 39.2 & \\
\hline $3000-7000$ & 23.3 & 76.7 & & 37.2 & 62.8 & \\
\hline $7001-12000$ & 28.6 & 71.4 & & 57.1 & 42.9 & \\
\hline $12001-18000$ & 50.0 & 50.0 & & 67.2 & 32.8 & \\
\hline $18001-25000$ & 47.2 & 52.8 & & 63.9 & 36.1 & \\
\hline$>25000$ riyals & 62.2 & 37.8 & & 68.9 & 31.1 & \\
\hline Job status & & & 0.011 & & & 0.236 \\
\hline Employed & 47.3 & 52.7 & & 63.3 & 36.7 & \\
\hline Unemployed & 35.7 & 64.3 & & 58.0 & 42.0 & \\
\hline Retired & 18.7 & 81.3 & & 43.7 & 56.3 & \\
\hline Health status & & & 0.296 & & & \\
\hline Healthy & 41.3 & 58.7 & & 60.9 & 39.1 & 0.693 \\
\hline Have one chronic condition & 34.1 & 65.9 & & 52.2 & 47.7 & \\
\hline Have multiple chronic conditions & 57.1 & 42.9 & & 57.1 & 42.9 & \\
\hline Have a genetic condition & 25.0 & 75.0 & & 66.7 & 33.3 & \\
\hline Major source of payment for $R_{x}$ & & & 0.415 & & & 0.170 \\
\hline Governmental institutions & 38.2 & 61.8 & & 55.4 & 44.6 & \\
\hline Insurance coverage & 46.9 & 53.1 & & 67.9 & 32.1 & \\
\hline Out of pocket & 39.6 & 60.4 & & 60.4 & 39.6 & \\
\hline $\begin{array}{l}\text { Values are presented as percentag } \\
\text { the dependence between the demo } \\
\text { generics. }{ }^{\dagger} p<0 .\end{array}$ & $\begin{array}{l}\text { 0) among } \\
\text { hic charac } \\
\text { s considere }\end{array}$ & $\begin{array}{l}\text { ticipants. }{ }^{*} \mathrm{~T} \\
\text { istics and the } \\
\text { tatistically si }\end{array}$ & $p$-values a & $\begin{array}{l}\text { from the } \\
\text { knowledg } \\
\text { Saudi Ri }\end{array}$ & $\begin{array}{l}\text { ii-square t } \\
\text { nd percept }\end{array}$ & $\begin{array}{l}\text { assessing } \\
\text { about }\end{array}$ \\
\hline
\end{tabular}

Table 3 - Participants' beliefs about the importance of the country of origin for medications.

\begin{tabular}{|c|c|c|c|c|c|c|}
\hline \multirow{2}{*}{ Items } & \multicolumn{3}{|c|}{ Knowledge (\%)* } & \multicolumn{3}{|c|}{ Perception (\%) } \\
\hline & Adequate & Inadequate & $P$-value & Positive & Negative & $P$-values \\
\hline $\begin{array}{l}\text { The effectiveness of a medication } \\
\text { depend on the country of origin }\end{array}$ & 60.2 & 64.0 & 0.254 & 60.9 & 64.8 & 0.245 \\
\hline $\begin{array}{l}\text { Locally manufactured generics } \\
\text { compete with the products of } \\
\text { developed countries }\end{array}$ & 60.3 & 42.4 & $0.003^{\dagger}$ & 63.9 & 28.3 & 0.001 \\
\hline $\begin{array}{l}\text { Locally manufactured generics are } \\
\text { superior than products of regional } \\
\text { countries }\end{array}$ & 51.6 & 36.87 & 0.017 & 52.5 & 28.3 & 0.001 \\
\hline \multicolumn{7}{|c|}{$\begin{array}{c}* \text { Percentage of participants in agreement with the statement among participants with adequate or inadequate knowledge } \\
\text { and positive or negative perception, therefore it cannot be combined to give a total of } 100 \% .{ }^{\dagger} p<0.05 \text { is considered } \\
\text { statistically significant }\end{array}$} \\
\hline
\end{tabular}


ones with adequate knowledge and positive perception on generics than those with inadequate knowledge and negative perception (Table 4). Among participants who had indicated using generics in the past, $68 \%$ used it for chronic conditions, $17 \%$ used it for acute conditions, and the remaining $15 \%$ used it for both; and approximately two-thirds of all were satisfied with their experience.

Relationship between respondents' knowledge and perception on generic medications. Approximately 82\% of the participants who had an adequate knowledge of generics had a positive perception on them. Thus, the study found a moderate and significant relationship between knowledge and perception on generics (standardized $\mathrm{C}=0.35, p<0.001$ ) (Table 5).

Discussion. This study identified an inadequate level of knowledge, yet a positive perception on generic medications among the Saudi population. Moreover, this study detected a moderate association between knowledge and perception on generics; and recognized the level of education as a significant determinant for the level of knowledge and perception on generic medications. Overall, people with adequate knowledge of generics and positive perception on them tend to have a better opinion on locally manufactured generics and were more likely to have used generic medications in the past and willing to re-use them in the future.

There is a scarcity of research on this topic in Saudi
Arabia, only one study has assessed the public perception regarding generic mediations, but it did not assess their knowledge on it. Albarraq ${ }^{8}$ found that more than $60 \%$ of participants preferred the use of brand medications over generics, approximately $40 \%$ of participants believed that generics were less effective, and 25\% believed that it had more adverse effects than their comparator brands. The previous findings suggested that there might be a general lack of knowledge on generics among the public in Saudi Arabia. This finding was confirmed in the current study using a specific scale on the questionnaire to measure and assess the public knowledge on generic medications, as only $40.5 \%$ of the participants were able recognize differences between brands and generics. In Jordan, participants had a better perception on generics than the participants in the current study $(75 \%$ vs. $60 \%) .{ }^{11}$ In United Arab Emirates, a study assessed the patient's knowledge and perception no generics among a cluster of renal patients. ${ }^{12}$ They found a better level of knowledge on generics than the current level in Saudi Arabia (60\% vs. $40.5 \%$ ). However, they assessed patients' knowledge using only one item "Do you understand the terms 'generic' and 'branded' in relation to medicines?", which might not be reliable in this case, as only one-third of the patients believed that generic was equivalent to brand medication. Similar to the findings from the present study, the level of education was a significant predictor for the participants' perception on generics. ${ }^{12}$

Table 4 - Participants' experience with generic medications.

\begin{tabular}{|c|c|c|c|c|c|c|}
\hline \multirow{2}{*}{ Item } & \multicolumn{3}{|c|}{ Knowledge (\%) } & \multicolumn{3}{|c|}{ Perception (\%) } \\
\hline & Adequate & Inadequate & $P$-value & Positive & Negative & $P$-value \\
\hline I have used generic medications in the past & & & $<0.001^{\dagger}$ & & & $<0.001$ \\
\hline Yes & 72.1 & 39.4 & & 64.3 & 35.2 & \\
\hline No & 27.9 & 60.6 & & 35.7 & 64.8 & \\
\hline $\begin{array}{l}\text { I am very satisfied with the results and I am thinking } \\
\text { about using more generic medications in the future* }\end{array}$ & & & $<0.001$ & & & $<0.001$ \\
\hline Yes & 80.3 & 51.3 & & 83.8 & 26.4 & \\
\hline No & 19.7 & 48.7 & & 16.2 & 73.6 & \\
\hline
\end{tabular}

*This results for the participants that had used generics in the past (answered Yes for the "I have used generic medications in the past" item on the questionnaire). ${ }^{\dagger} P<0.05$ is considered statistically significant

Table 5 - Relationship between respondents' knowledge and perception of generic medications.

\begin{tabular}{lccc}
\hline & \multicolumn{2}{c}{ Perception $(\%)$} & \\
Knowledge & Negative & Positive & Total \\
\hline Inadequate & $130(55.1)$ & $106(44.9)$ & $236(59.5)$ \\
Adequate & $29(18.0)$ & $132(82.0)$ & $161(40.6)$ \\
Total & $159(40.1)$ & $238(60.0)$ & $397(100)$ \\
\hline
\end{tabular}

Values are presented as numbers and percentages (\%). 
In order to realize a change in any situation, you would need to have a mutual agreement between all stake holders related to the conflict under investigation. In the case of generic medications, we need to ensure that there is an adequate knowledge and positive perception on generics from the prescribing physicians, dispensing pharmacists, and consuming patients. The current study found a general lack of knowledge on generics from the consumers' perspective; thus, we reviewed the current situation from the other 2 perspectives. A cross sectional questionnaire-based study involving 178 physicians was conducted in Saudi Arabia and found that only 44\% of them were able to explain bioequivalence to their patients. One-half knew the price difference between brands and generics and only one-half reported that local generics should be substituted for brands. ${ }^{13}$

A qualitative study was conducted in Alahsa, Eastern side of Saudi Arabia, for the dispensing pharmacists, to explore the factors that community pharmacists consider when dispensing brand or generic medications. The study found that generics were usually available in stock for most common medications, and pharmacists practicing in hospital-affiliated pharmacies preferred the use of branded medications and avoided switching from brands to generics, due to concerns on quality of generics. While pharmacists practicing in non-hospital affiliated pharmacies revealed that patients' appearance was a main factor that influenced their decision to dispense generics or brands. ${ }^{14}$ Another study evaluated community pharmacists' knowledge and perception regarding generic medications in Saudi Arabia and found that community pharmacists were uncertain on the efficacy and safety of generic medications. Substantial percentage of them reported that patients' choice as well as product bonuses, offered by pharmaceutical companies, were influencing their offering for generic substitutes. However, patients' preference was the most important factor influencing the pharmacists' generic drug substitution practice. ${ }^{15}$ Another study was conducted in Makkah region, Western side of Saudi Arabia, to investigate the community pharmacist's knowledge, attitude and perception on generic medications. The study found that only $22 \%$ of participants answered all questions on generics correctly and two-thirds of all were supporting the use of generic substitution. Besides the cost of medication, similar to the previous study, patients' request was a major determinant for dispensing a generic medication. ${ }^{16}$

The inadequate level of knowledge from physicians and community pharmacists recognized in the literature, along with the findings from the present study, indicate that we need to educate prescribers, community pharmacists, and patients on generic medications as well as introduce and implement a generic substitution policy to regulate the substitution practices of generics, especially in community pharmacies. ${ }^{13-16}$ Unfortunately, there is no agreement on strategies that can be used to promote prescribing, dispensing, or utilization of generics; therefore, more research is needed to investigate this topic in order to come up with strategies that would increase the level of knowledge and utilization of generics by the public. ${ }^{7,17}$

Over the past years, the establishment and launching of the new electronic prescribing and dispensing system "Wasfaty" by the National Unified Procurement Company (NUPCO) made pharmacists and pharmacy technicians in healthcare facilities a valuable resource that can be empowered and employed as health educators. In this case, they can educate physicians, patients, and pharmacists in the community setting to advance their knowledge and improve their perception on generic medications. Moreover, the launching of Wasfaty ${ }^{\oplus}$ should promote the prescribing of generic medications in governmental healthcare facilities, and hopefully be expanded to other semi-governmental and private healthcare facilities in the country. However, this will need to be braced by implementing high-quality measures for all medications that will be dispensed through Wasfaty ${ }^{\oplus}$. The present study introduced a short and quick scale that assesses the public knowledge and perception on generics which can be used in the future to re-assess the situation or measure the effectiveness of any awareness campaign that should be conducted.

Study limitations. Data were collected through convenience sampling to examine the current level of knowledge and perception from the public toward generics and their experience using it. Therefore, the findings may not be generalized to the national level, but it can be used to identify segments of the population that needs to be educated on generics in order to improve the current level of knowledge on generics. In addition, the majority of the participants were from the young age groups; therefore, the findings may not reflect the knowledge and perception among the older segment of the population, thus another study should be conducted to assess the level of knowledge among the older cohort of the Saudi population. Similarly, the highest educational achievement for the participants was skewed toward the higher level of the scale, thus the findings may not reflect the knowledge and perception among people with a lower level of educational achievement. Though, if knowledge among people with higher level of education was inadequate we can expect that to be inadequate among people 
with a lower level of education. The use of WhatsApp for sending invitations and recruiting the participants limited the inclusion of people that does not use this type of technology. Therefore, the findings of this study cannot be generalized to these people and they need to be recruited and evaluated in future research using other methods.

In conclusion, the study recognized that the public level of knowledge and perception on generics is an area that need significant improvement in order to increase the use of generic medications. The use of generics is a major opportunity for decision-makers in the Saudi healthcare system to promote cost-savings strategies while maintaining or improving the quality of care. The increase in the utilization of generic medication by the public will then be translated into saving on budget for the overall healthcare system in Saudi Arabia. Since locally manufactured medications were publicly acceptable, then the local manufacturing of medications should be supported by different means. The increase in utilization of generic medications, along with the increase in production of local manufacturing of medications, which will come as a result of the support to this sector, will improve the efficiency of our budget and move us one step near the realization of the Saudi vision 2030.

Acknowledgment. The authors would like to extend their appreciation to King Saud University, Riyadh, Kingdom of Saudi Arabia for funding this work through the Researcher Supporting Project (no. RSP-2019/77). We would also like to thank Polished Paper (www.polishedpaper.com) for English language editing of this manuscript.

\section{References}

1. Stadhouders N, Kruse F, Tanke M, Koolman X, Jeurissen P. Effective healthcare cost-containment policies: A systematic review. Health Policy 2019; 123: 71-79.

2. Johansen ME, Richardson C. Estimation of potential savings through therapeutic substitution. JAMA Intern Med 2016; 176: 769-775.

3. Warraich HJ, Salami JA, Khera R, Valero-Elizondo J, Okunrintemi V, Nasir K. Trends in use and expenditures of brand-name atorvastatin after introduction of generic atorvastatin. JAMA Intern Med 2018; 178: 719-721.

4. Hassali MA, Alrasheedy AA, McLachlan A, Nguyen TA, Al-Tamimi SK, Ibrahim MI, et al. The experiences of implementing generic medicine policy in eight countries: A review and recommendations for a successful promotion of generic medicine use. Saudi Pharm J 2014; 22: 491-503.
5. U.S.-Saudi Arabian Business Council (USSABC). New horizons and opportunities in the Saudi healthcare sector: USSABC; 2017. Available from URL: https://us-sabc.org/new-horizonsand-opportunities-in-the-saudi-healthcare-sector/

6. Emeka PM, Al Ahmed A. Extents of generic prescribing in hospitals and community pharmacies for diabetic and hypertensive outpatients in Eastern region of Saudi Arabia. $J$ Young Pharm 2017; 9: 280-283.

7. Alhawassi TM, Abuelizz HA, Almetwazi M, Mahmoud MA, Alghamdi A, Alruthia YS, et al. Advancing pharmaceuticals and patient safety in Saudi Arabia: A 2030 vision initiative. Saudi Pharm J 2018; 26: 71-74.

8. Albarraq A. Consumers' perceptions on generic medicines in Taif city, Saudi Arabia. Saudi J Health Sci 2013; 2: 18-22.

9. Saudi Food and Drug Authority (SFDA). What is a generic medication? Available from URL: https://www.sfda.gov.sa/en/ drug/awareness/news/pages

10. Rashidi Y, Vaniea K, Camp JL. Understanding Saudis' privacy concerns when using WhatsApp. Usable Security and Privacy 2016 Conference; 21 February 2016. San Diego: California; 2016. p. 1-8.

11. El-Dahiyat F, Kayyali R. Evaluating patients' perceptions regarding generic medicines in Jordan. J Pharm Policy Pract 2013; 6: 3 .

12. Al Ameri M, Mohamed W, Makramalla E, Shalhoub B, Tucker A, Johnston A. Renal patients' views on generic prescribing and substitution: example from the United Arab Emirates. East Mediterr Health J 2013; 19: 373-381.

13. Salhia HO, Ali A, Rezk NL, El Metwally A. Perception and attitude of physicians toward local generic medicines in Saudi Arabia: A questionnaire-based study. Saudi Pharm J 2015; 23: 397-404.

14. Albadr Y, Khan TM. Factors influencing community pharmacist decision to dispense generic or branded medicines; Eastern Province, Alahsa, Saudi Arabia. Saudi Pharm J 2015; 23: 143-146.

15. Wajid S, Al-Arifi M, Al Nomay H, Al Mousa Y, Babelghaith S. Knowledge and perception of community pharmacists' towards generic medicines in Saudi Arabia. Biomed Res 2015; 26 : 800-806.

16. Alkhuzaee FS, Almalki HM, Attar AY, Althubiani SI, Almuallim WA, Cheema E, et al. Evaluating community pharmacists' perspectives and practices concerning generic medicines substitution in Saudi Arabia: A cross-sectional study. Health Policy 2016; 120: 1412-1419.

17. Moe-Byrne T, Chambers D, Harden M, McDaid C. Behaviour change interventions to promote prescribing of generic drugs: a rapid evidence synthesis and systematic review. BMJ Open 2014; 4: e004623. 